\title{
Strategic thinking, strategic planning, strategic innovation and the performance of SMEs: The me- diating role of human capital
}

\author{
Nagwan AlQershi ${ }^{a^{*}}$
}

${ }^{a}$ University Tun Hussein Onn Malaysia, Malaysia

\section{H R O N I C L E}

Article history:

Received: June 20, 2020

Received in revised format:

August 302020

Accepted: September 18, 2020

Available online:

September 23, 2020

Keywords:

Strategic Thinking (ST)

Strategic Planning (SP)

Strategic Innovation (SI)

Human Capital (HC)

Performance (PE)

\section{A B S T R A C T}

Strategists have unique skills and abilities to connect the past and the present in order to predict what might happen in the future. The current study is the culmination of a number of research ideas in the field of Strategic Thinking (ST), Strategic Planning (SP) and Strategic Innovation (SI) in relation of Human Capital (HC). The survey method was used to collect data from 235 SMEs in the manufacturing industry of Yemen. Results indicate that ST, SP and SI have a significant effect on HC. The mediating effects of HC on the relationship between ST, SP and SI and SMEs' performance were also examined. Results indicate that HC mediates the relationship between ST, SP and SI and firm performance. The findings of this study offer important insights for managers of SMEs, researchers and policymakers to further understand the effects of ST, SP SI, HC and SMEs' performance. SMEs should also be encouraged to develop their ST, SP, SI and HC to improve their performance. Finally, this study serves not only to clarify the mechanism between HC and SMEs' performance, but also to generalize the ST, SP and SI results in the Yemen and Middle East context.

(C) 2021 by the authors; licensee Growing Science, Canada

\section{Introduction}

The SME sector performs an important function in the Yemeni economy (YMIT, 2019; AlQershi et al., 2018; OECD, 2017; World Bank, 2015), including the manufacturing small and medium enterprises (SMEs) (OECD, 2017; World Bank, 2015). They are key employers and create opportunities for the millions of people coming into the labor market each year (OECD, 2017; Aga et al., 2015). At the same time, Yemen is one of the least developed nations in the region with about $42 \%$ of the populace living below the poverty line. Yemen ranks 149 among 171 countries in terms of human development (OECD, 2017). The unemployment rate reached $12.81 \%$ in 2019 (Statista, 2019). It is important to note that SMEs perform a crucial function in the economies of all countries by making jobs available and acting as suppliers for larger enterprises. From a survey conducted in 2019, SMEs in Yemen were considered as the solution to economic problems including worsening unemployment and poverty (YMIT, 2019). With the large number of Yemeni manufacturing SMEs, it is surprising that they contribute so little to the country's gross domestic product (GDP), but they have been facing problems in terms of performance (AlQershi et al., 2019; YMTEVT, 2018; World Bank, 2015; Sky News, 2012; Aljazeera, 2012). The World Bank (2015) critically appraised the performance of the Yemeni economy in recent years and concluded that it is very weak, especially that of the manufacturing sector. The World Bank blamed the low performance of the manufacturing sector on a low level of strategic thinking, planning and innovation (World Bank, 2015; GIIR, 2017). Yemeni SMEs face numerous problems, such as poor infrastructure, inadequate technical support, problems in securing and adopting new technologies, an inadequate supply of skilled workers, and lack of opportunities for financing (Alqershi et al., 2019; YMIT, 2019; YMTEVT, 2019). As one of the poorest countries in the world, with a GDP per capita of USD 2,820.8 (World Bank, 2016), Yemen largely relies on international aid, assistance from its oil-rich neighbors, and remittances sent by expatriates. The manufacturing facilities for major sectors have been shown to be on the decline. Based on reported statistics, the problems faced by the Yemeni economy

* Corresponding author.

E-mail address: nagwan@uthm.edu.my (N. AlQershi) 
include lack of interest in industrial facilities, underdeveloped industries that cannot compete with neighboring countries, and the low level of the national economy; the annual GDP of manufacturing industries is $4 \%$, due to the low performance of Yemeni production as well as the high inflation rate of 11\% (World Bank, 2016). Moreover, the value of imports accounts for a significant proportion of Yemen's annual budget: 41\% (World Bank, 2016). The statistics also show that the total budget of the Yemeni economy hinges largely on oil, accounting for up to $93 \%$ of the GDP. Industrial exports are estimated to be at a low of $0.07 \%$, indicating the extent of the problem. SMEs are therefore unable to make a good contribution unless they perform satisfactorily. As already indicated, it is their performance that actually contributes to the individual entrepreneur and to society as a whole (Buli, 2017; Ren et al., 2015). Hence, SME performance is a subject that deserves attention. Although SMEs generally are important contributors to national development, this study focuses on the performance of manufacturing SMEs because this sector is considered as a growth pillar of contemporary economies (Chege \& Wang, 2020; Mahmood et al., 2015; Edinburgh Group, 2013). With the current decline in the price of oil, Yemen must place greater emphasis on the productivity (performance) of its manufacturing sector. A vibrant manufacturing sector will be able to create jobs for the large number of unemployed youth. Thus, the focus of this study is on the performance of manufacturing SMEs in Yemen.

\section{Literature Review}

\subsection{Strategic Thinking}

Strategic thinking demands creativity, foresight and insight. Foresight indicates shadowing the future; that is, foreseeing its shape before it materializes. Insight pivots on the perimeter uncovering methods that give birth and sense to the future (Zahra \& Nambisan, 2012). Thinking strategically requires research, analysis and forethought in order to create a plan for how you will proceed as an organization. Therefore, the ability to think strategically provides another dimension to the process of strategy making. It recognizes that strategic thinking and planning are distinct but interrelated and complementary thought processes (Training, 2011; O'Shannassy, 1999). According to Heracleous, (1998) there is still confusion in the literature over the distinction between the two concepts, strategic planning and strategic thinking. Strategic thinking usually refers to a creative, divergent thought process but strategic planning to a programmatic, analytical thought process. The ambiguity stems from the fact that, despite continual usage of the terms in the above ways, various scholars often use these concepts in fundamentally different ways. While there are distinct thinking styles for some ST and SP which are both useful at various stages of the strategic management process (e.g. Mintzberg et al., 2005), for others, strategic thinking is not so much creative as analytical (Porter, 1991); for some , strategic planning had remained an analytical activity but the organizational practice surrounding it have been transformed ; for others, the main aim of SP analytical methods is to facilitate creativity (ST); and lastly for others, SP is futile and should be scrapped in favor of ST. According to Tavakoli and Lawton (2005) some scholars argued that strategic thinking is "adapt at interpreting, analyzing and applying information" and arrange the same information in more than one way, thereby generating more alternative courses of action' in the process of achieving determined objectives (Stumpf, 1989). Furthermore Graetz, (2002) argued that ST involves thinking in time. Strategic thinker understands the interconnectivity of yesterday, today and tomorrow. And based on above arguments, the present study hypothesizes that:

\section{H1: Strategic thinking is positively related to human capital.}

\subsection{Strategic Planning}

Strategic planning is the procedure of authenticating and establishing a direction for business activities by evaluating both the present and future objectives (Henderson \& Hines, 2019). Strategic planning is the mechanism by which an organization determines its vision and strategies, and makes decisions about allocating its human wealth and other resources to support this strategy (Allison \& Kaye, 2011). It is generally believed that strategic planning could lead to new unique positions, business models, business processes and/or positioning in relation to rivals in the light of enhanced performance by investment in human capital (Rothwell \& Kazanas, 2003). The firm's adoption of a new strategy could allow it to either improve its performance or regress it through the use of strategic planning (Donkor et al., 2018). Hence, to outperform its rivals in the face of world change, a firm has to use appropriate strategies in order to keep abreast and to thrive in a changing environment (Yadav, Pal, Patra and Yadav, 2020; Albrechts et al., 2016). Few studies have been devoted to examining strategic planning in countries with unique cultural practices, such as Yemen and those of the Middle East, so this is an interesting topic for further investigation (Al-Kilani, 2019; Omar, 2019; Al-Shammari \& Hussein, 2008). However, these studies have examined SP only in the services sector although they should apply to all industries, including manufacturing; their absence in Yemeni and Arabic manufacturing firms is an important gap for this study to investigate. Based on previous studies that found a significant relationship between SP and $\mathrm{HC}$, the present study hypothesizes as follows:

\section{H2: Strategic planning is positively related to human capital.}

\subsection{Strategic Innovation}

Strategic innovation means an innovation in one's business model that leads to a new way of performing (Alqershi et al., 2020; Charitou \& Markides, 2002). Strategic innovation guarantees that organizations do not fall into the trap of following accepted procedures and administrative patterns which cannot, regardless, remain dominant since every one of their adversaries is doing similar things. With a specific end goal in a focused commercial center, an organization requires uniqueness 
involving an astute, self-strengthening framework or plan of action (Derrick \& Soren, 2007). Previous studies have consistently linked SI to HC; for example, Alqershi et al. (2019) concluded that HC can improve SI. Khan, Hussain, Shahbaz, Yang and Jiao, (2020) found that innovation also has a direct effect through HC. According to AlQershi et al. (2018), strategic innovation increases organizational efficiency by the efficient use of human capital. In contemporary business, the ability to form strategic innovation is vital in order to provide an effective and efficient performance. Thus, strategic innovation in particular is a contribution of the present study in the Yemeni context. Previous studies on SMEs' performance in Yemen (Nusair \& Osman, 2016; Fararah et al., 2014; Alhammadi \& Shahadan, 2014; Fararah \& Al-Swidi, 2013; Jabeen et al., 2013) have ignored innovation and human capital and this is a very serious gap in the literature. In the highly competitive business environment of the 21 st century, firms need to embrace innovation in order to survive and grow to provide value for stakeholders: owners, employees, and society and the economy in general. Horibe (2016) believed that one way for organizations to be constantly innovative, win in the competitive market and sustain their growth, is by moving from competitive advantage strategies towards the innovation path. Mowery, Nelson, Sampat and Ziedonis (2015) stated that current innovative technological advances are making the markets very dynamic and unstable for business. Thus, finding innovative solutions for differentiation and sustaining growth has become even more important for organizations. Based on the above discussion on the relationship between the variables, the present study hypothesizes as follows:

\section{H3: Strategic innovation is positively related to human capital.}

\subsection{Human Capital}

Human capital is at the heart of organizations, relating to employees' knowledge, skill, competence, innovation and capability; moreover, employees generate intellectual capital through their competence, attitude and intellectual agility (Subramaniam \& Youndt, 2005). According to Khalique, Shaari, Abdul and Isa (2011), competence includes skills and education; attitude covers the behavioural dimensions of the employee's work; while intellectual agility is based on innovativeness and solution of business problems (Bontis et al., 2000). Human capital consists of the knowledge, experience and talent of employees and is a major source of value addition. HC is also recognized as an important and vital ingredient for the success of companies in a competitive environment. The main ingredients of the production-based economy were land, labour, capital and physical assets. However, in the present knowledge-based economy, $\mathrm{HC}$ has become more important than physical assets in adding value (Hejazi et al., 2016). It has also been recognized as the most important source of performance of various organizations, leading to increased innovation capability, organizational performance and national economic growth (Sivalogathasan $\& \mathrm{Wu}$, 2015). Several researchers have investigated the HC and performance relationship. Alqershi et al., (2008), in their study of the relationship between HC and performance, found a significant relationship. Sharabati et al., (2010) observed a significant direct influence of human capital on performance. Zerenler et al. (2008) explored the relationship between HC and innovation performance, and found that $\mathrm{HC}$ has a significant role in improving the features of existing services and products. Similarly, $\mathrm{HC}$ and its relationship with organizational performance was investigated among manufacturing firms in Russia; the study found that human capital has positive effects on organizational performance, clarifying a quarter of the variations in the latter (Andreeva \& Garanina, 2016). Finally, the World Bank (2015) stated that Yemeni firms should make provision for training SME personnel across the country; increasing the level of human capital requires a large amount of training. Unfortunately, SMEs are usually too poor to afford the cost of training in modern techniques. What government can do is to encourage such training especially through providing subsidies to SMEs. Based on this discussion and the report of the World Bank (2015), which spells out that human capital is a major factor in improving the Yemen economy, the present study hypothesizes:

\section{H4: Human capital mediates the relationship between ST, SP and SI and SMEs' performance.}

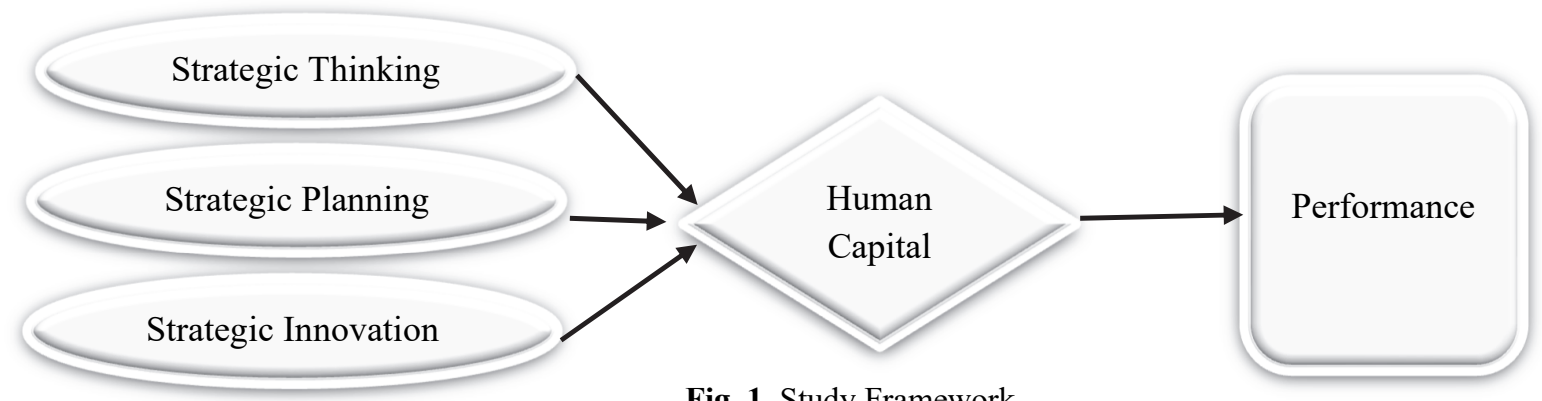

Fig. 1. Study Framework

\section{Methodology}

\subsection{Sample and Data Collection}

The study's target population is Yemeni manufacturing SMEs, identified from the 2019 Directory of SME firms (Ministry of Trade and Industry of Yemen, 2019), and selected for its pivotal role in the Yemeni economy. A quantitative cross-sectional survey research design was employed, and a total of 397 self-administered questionnaires was distributed to SME managers; 251 responses were retrieved and 16 of these were incomplete, leaving a total of 235 responses for analysis. The unit of 
analysis is the organization level, where the managers of the SMEs are representatives of their firms. The managers are key respondents with their knowledge and authority in planning and in making decisions, and therefore the most suitable individuals to reply to the survey questions.

\subsection{Study Measures}

The measurements of this study were adopted from literature. A 5-point Likert scale 1 (strongly disagree) to 5 (strongly agree) was used to rate the responses from the survey, an efficient way to assess the judgment of the participants and an appropriate method for gathering accurate data (Franklin \& Foa, 2002; Armstrong, 1987). Strategic thinking was measured with an initial 10-item scale adopted from Liedtka (1998) and Napier and Albert (1990). In measuring strategic planning, we adopted AlShammari and Hussein's (2008) measures. Strategic innovation was initially assessed using nine items adopted from Yang (2014). Human capital was measured with six items adopted from the work of Bontis, Sharabati and Jawad (2010); finally a 5-point Likert scale ( $1=$ much lower to $5=$ much higher $)$ was used to measure firms' performance, using measures suggested by a number of researchers, including Mokhtar et al. (2014); Kaplan and Norton, (1992); and Gupta and Govindarajan (1984). Table 1 displays the study measures.

Table 1

Study Items

\section{Strategic Thinking Items}

Our organization have ability to formulation and design of future situation of main processes of organization.

Our organization have ability to select and use of appropriate patterns from organization's background.

Our organization always benefiting from past events for future prediction.

Our organization works on establishing connection among past, present and future.

Our organization have vision resulted of internal and external analysis.

Our organization have the ability to manage any conflicts and struggle among group members.

Our organization have awareness about organization's strengths and weaknesses.

Our organization always seeking on developing organizational culture aligned with creativity and change.

Our organization always trying to creating a climate full of positive thinking, honesty and transparency.

Our organization encourage the staff to changing dismantled way of thinking to systematic way of thinking.

Strategic Planning Items

Our organization has long-range plan includes the specification of objectives and goals.

Our organization has long-range plan includes the selection of long-range strategies

Our organization has long-range plan includes the determination of future resources required.

Our organization have procedures for anticipating or detecting error in, or failures of, the plan for preventing or correcting

Our organization have some attempt to account for factors outside of the immediate environment of the firm.

Strategic Innovation Items

Our organization always makes new products, or upgrade old products to meet consumer demands.

Our organization uses new designs for branding and entire product categories to show the inner spirit and unique culture

Our organization develops incorporates a financial system in order to improve operational efficiency and reduce the costs

Our organization makes improvements in the quality of some materials.

Our organization has found new ways to deliver products that customers already use and appreciate, like direct sales,

Our organization develops new marketing methods and ideas and ways of advertising, public relations, promotions, and

Our organization has increased the use of high technology for transformation and flow of goods for external efficiency,

Our organization improves new customer interaction channels, distribution systems or technological concepts based on

Our organization uses some methods to acquire goods or services at the best possible total cost.

\section{Human Capital Items}

The competence of the organization's employees as a whole is equal to the most ideal level (matching their work re-

Our organization gets the most out of its employees when they cooperate with one another in team tasks.

Our organization's employees undergo continuous training programmers every year.

Our organization's employees continuously learn from others.

The company devotes a lot of time and effort to updating and developing employees' knowledge and skills.

Our organization's staff are highly professional.

\section{Performance Items}

Return on Investment

Sales Volume

Market Share

Profitability Growth

Cash Flow

New Product Development.

Research and Development Activates

Cost Reduction Program 


\section{Results}

\subsection{Direct Relationship}

Analyzing the findings of the study model, we deduced that all relationships have strong and satisfied support. The structural model's full estimates are presented in Fig. 2. In hypotheses 1, 2 and 3, we predicted positive relationships between SI, SP, ST and human capital. As Figure 2 suggests, we found that SI, SP, ST has a significant positive influence on human capital $(\beta=0.41, \mathrm{t}=8.12, \mathrm{p}<0.03) ;(\beta=0.32, \mathrm{t}=3.41, \mathrm{p}<0.01)$ and $(\beta=0.52, \mathrm{t}=4.71, \mathrm{p}<0.03)$ respectively, supporting $\mathrm{H} 1-\mathrm{H} 3$.

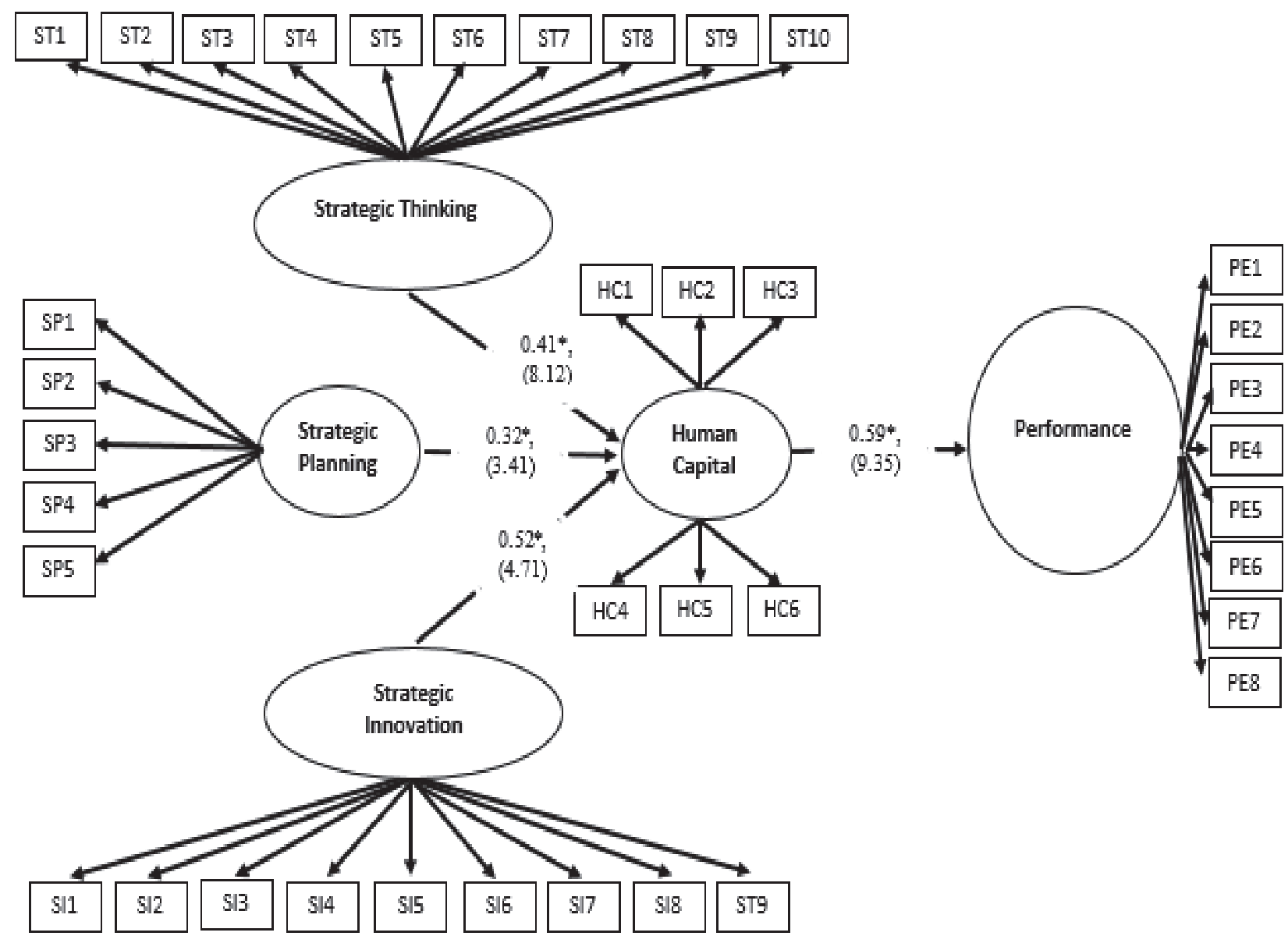

Fig. 2. The results of statistical test

$\chi^{2}=183.27$, d.f. $=81, p$-value $=0.000, C F I=0.93, G F I=86, R M S E A=78 ; *$ Significant at the p-value of 0.05 or less.

\subsection{A Mediating Role of Human Capital}

In the mediation relationship (H4), the study tried to determine the mediating role of human capital between SI, SP and ST and firm performance. If the indirect influence of SI, SP and ST on firms' performance is significant in comparison to the direct influence of these constructs on performance, this demonstrates the significant role of human capital in implementing SI, SP and ST. To empirically test this mediation effect, an additional model was analyzed, adding a direct path from SI, SP and ST to performance. The chi-square $\left(\chi^{2}\right)$ values of the proposed model were then compared with those of the alternative model (Westland, 2016). $\chi 2$ difference analysis indicated that the addition of a direct path does not enhance the fit significantly at the 0.05 level (study model: $\chi 2=183.27$ with df 81 vs. alternative model: $\chi 2=183.91$ with df 82 ). The extent of direct and indirect influence between SI, SP and ST on performance was also compared. The total influence of SI, SP and ST on performance is 0.81 , with an indirect influence of 0.50 and a direct influence of 0.17 . Therefore, the study concludes that the indirect influence through human capital is dominant in explaining the total influence between SI, SP and ST and firms' performance. 
Table 2

The results of confirmatory factor analysis

\begin{tabular}{|c|c|c|c|}
\hline Construct Indicator & Estimates & t-value & SMC \\
\hline \multicolumn{4}{|l|}{ Strategic Thinking } \\
\hline ST1 & 1.02 & 10.23 & 0.62 \\
\hline ST2 & 0.91 & 11.71 & 0.54 \\
\hline ST3 & 1.21 & 9.84 & 0.61 \\
\hline ST4 & 1.43 & 8.06 & 0.72 \\
\hline ST5 & 0.83 & 11.02 & 0.68 \\
\hline ST6 & 1.03 & 12.41 & 0.58 \\
\hline ST7 & 1.26 & 11.08 & 0.53 \\
\hline ST8 & 1.21 & 14.62 & 0.62 \\
\hline ST9 & 0.86 & 10.31 & 0.76 \\
\hline ST10 & 0.97 & 16.81 & 0.69 \\
\hline \multicolumn{4}{|l|}{ Strategic Planning } \\
\hline SP1 & 1.02 & 17.54 & 0.68 \\
\hline SP2 & 0.81 & 11.48 & 0.58 \\
\hline SP3 & 0.95 & 18.67 & 0.69 \\
\hline SP4 & 1.29 & 14.93 & 0.72 \\
\hline SP5 & 1.32 & 18.21 & 0.78 \\
\hline \multicolumn{4}{|l|}{ Strategic Innovation } \\
\hline SI1 & 0.84 & 20.43 & 0.61 \\
\hline SI2 & 1.07 & 19.46 & 0.66 \\
\hline SI3 & 0.75 & 15.81 & 0.68 \\
\hline SI4 & 0.95 & 13.85 & 0.51 \\
\hline SI5 & 0.91 & 21.34 & 0.58 \\
\hline SI6 & 1.13 & 19.72 & 0.61 \\
\hline SI7 & 0.98 & 11.81 & 0.52 \\
\hline SI8 & 1.09 & 12.07 & 0.68 \\
\hline SI9 & 0.91 & 14.34 & 0.69 \\
\hline \multicolumn{4}{|l|}{ Human Capital } \\
\hline $\mathrm{HC} 1$ & 1.08 & 9.37 & 0.63 \\
\hline $\mathrm{HC} 2$ & 1.19 & 12.00 & 0.77 \\
\hline $\mathrm{HC} 3$ & 0.93 & 16.36 & 0.80 \\
\hline $\mathrm{HC} 4$ & 0.81 & 18.09 & 0.72 \\
\hline HC5 & 0.96 & 17.36 & 0.68 \\
\hline HC6 & 1.07 & 20.61 & 0.82 \\
\hline Performance & & 19.50 & 0.74 \\
\hline PE1 & 0.88 & 21.72 & 0.83 \\
\hline PE2 & 0.95 & 18.05 & 0.61 \\
\hline PE3 & 1.28 & 19.17 & 0.53 \\
\hline PE4 & 1.17 & 16.42 & 0.40 \\
\hline PE5 & 0.84 & 15.06 & 0.61 \\
\hline PE6 & 0.90 & 18.11 & 0.67 \\
\hline PE7 & 1.21 & 12.21 & 0.78 \\
\hline PE8 & 0.99 & 17.05 & 0.81 \\
\hline
\end{tabular}

\section{Discussions and Contributions}

This study made several unique theoretical contributions regarding management constructs: human capital, strategic thinking, strategic innovation, strategic planning, and SMEs' performance. The empirical evidence for the theoretical relationships proposed in the research framework highlights and confirms the significant direct and indirect relationships. It specifically provides evidence of the key role of human capital in mediating the relationships between ST, SI, SP and SME performance in the context of a developing, Middle Eastern nation, Yemen. The study fills the literature gap of quantitative studies dedicated to performance of SMEs.

With little evidence for the relationship between ST, SI, SP and performance, it was imperative to identify the overall mechanism and the conditions by which ST, SI, SP successfully improve business effectiveness (AlQershi et al., 2018). To this end, the study investigated the mediating role of human capital in the relationship between ST, SI, SP and SME performance. It designed a comprehensive framework demonstrating that strategic thinking, strategic planning and strategic innovation and human capital lead to improved capability, in turn enhancing firms' performance. 
The empirical findings of this study reveal that the entrepreneurial orientation, comprising strategic thinking and innovativeness and development of human capital, are significantly related to performance. SME managers in Yemen should train their staff on a continuing basis. Although training appears to be costly and is therefore avoided by SMEs, managers must understand that the benefit is greater than the cost.

The results also have unique managerial implications for both academics and practitioners. First, the efficiency of companies has a vital role in strategic work implementation. Our results showed that strategic thinking, strategic innovation and strategic planning improve firm performance through human capital. This means that strategic thinking, strategic innovation and strategic planning alone are not sufficient, and improved performance was realized when firms facilitated its human capital. Thus, the study strongly recommends that managers pay more attention to raising their human capital by utilizing strategic thinking, strategic innovation and strategic planning. Finally, this study reinforces the significance of strategic thinking, innovation and planning in order to boost human capital effectively. Based on this study's findings, it is very important for firms to pay attention to strategic thinking, strategic innovation and strategic planning and provide the training to their employees to encourage them to enhance their performance.

\section{Limitations and Future Research}

This study has several limitations. First, the sample was limited to manufacturing SMEs, limiting the findings' generalizability to other sectors. So future researchers may prefer a probabilistic sampling method. Second, the partial mediating effects of $\mathrm{HC}$ indicate that other variables mediate the link between strategic thinking, strategic planning, strategic innovation and SMEs' performance. Future studies may investigate the mediating role of other dimensions of intellectual capital such as innovation capital. Finally, this study used a quantitative approach, but future studies might investigate the extent of the study variables by using qualitative techniques to provide in-depth knowledge of the issues. This would help to understand how SMEs can implement strategic thinking, planning and innovation for performance. Despite the insights achieved, however, little attention has previously been devoted to examining this relationship in countries with unique cultural practices, such as those of the Middle East, so this is an interesting topic for further investigation, building on these results and further expanding our knowledge of this significant research topic.

\section{Conclusions}

In conclusion, this study can be beneficial to practitioners, academics and policy makers by enhancing their understanding of the importance of implementing strategic thinking, strategic planning and strategic innovation, by exploring the holistic roles by which human capital leads to organizational performance; it will assist firms in learning what to do to achieve high performance. Additionally, it is evident that human capital plays a vital role in improving firm's ability from several aspects. Also, in order to utilize strategic thinking, strategic planning and strategic innovation and human capital effectively, firms need to focus on how to develop knowledge rather than on what knowledge to develop, taking quick action in developing training for employees.

\section{Acknowledgement}

The author would like to thank Faculty of Technology Management and Business (FTMB) University Tun Hussein Onn Malaysia (UTHM) for funding this research (under research fund E15501, Research Management Center, UTHM). The support given by Research Center, UTHM for providing the facilities to perform this research is highly appreciated.

\section{References}

Aga, G. A., Francis, D., \& Rodriguez-Meza, J. (2015). SMEs, age, and jobs: A review of the literature, metrics, and evidence. Albrechts, L., Balducci, A., \& Hillier, J. (Eds.). (2016). Situated practices of strategic planning: An international perspective. Routledge.

Alhammadi, A., \& Shahadan, F. (2014). The determinants of growth performance of small services enterprises in Yemen. Jurnal Ekonomi Malaysia, 48(1), 35-48.

Aljazeera. (2012), "Retrieved from" http://www.aljazeera.net(2012)/programs/economy and people/2012. https://www.youtube.com/watch?v=wHJp8pKq xA

Al-Kilani, B. M. (2019). Strategic Planning in Higher Education in the Arab World: Toward an Effective Implementation to Overcome Challenges. In Strategic Thinking, Planning, and Management Practice in the Arab World (pp. 250-274). IGI Global.

Allison, M., \& Kaye, J. (2011). Strategic planning for nonprofit organizations: A practical guide and workbook. John Wiley \& Sons.

AlQershi, N. A. (2019). Innovation Capabilities as a Source of Inspiration: Towards a Sustainable Competitive Advantage in Yemeni Manufacturing Industry. International Journal of Knowledge Management and Practices, 7(1), 1.

AlQershi, N., Abas, Z. B., \& Mokhtar, S. S. M. (2018). Strategic innovation and its impact on manufacturing SME performance in Yemen. 
AlQershi, N., Abas, Z., \& Mokhtar, S. (2020). The intervening effect of structural capital on the relationship between strategic innovation and manufacturing SMEs' performance in Yemen. Management Science Letters, 11(1), 21-30.

AlQershi, N., Abas, Z. B., \& Mokhtar, S. S. M. (2019). Investment in the Hidden Wealth of Intellectual Capital and Its Effect on Competitive Advantage. Anwesh, 4(1), 17.

AlQershi, N., Abas, Z. B., \& Mokhtar, S. S. M. (2019). Prospecting for structure capital: Proactive strategic innovation and the performance of manufacturing SMEs in Yemen. International Journal of Entrepreneurship, 23(3), 1-19.

AlQershi, N., Abas, Z. B., \& Mokhtar, S. S. M. (2019). The Mediating Effect of Human Capital on the Relationship between Strategic Innovation and the Performance of Manufacturing SMEs in Yemen. Organizations and Markets in Emerging Economies, 10(1), 57-77.

AlQershi, N., Abas, Z., \& Mokhtar, S. S. M. (2018). Strategic innovation as driver for SME performance in Yemen. Journal of Technology and Operations Management, 13(1), 30-41.

Al-Shammari, H. A., \& Hussein, R. T. (2008). Strategic planning in emergent market organizations: empirical investigation. International Journal of Commerce and Management.Westland, J. C. (2016). STRUCTURAL EQUATION MODELS. Springer International PU.

Anderson, J. C., \& Gerbing, D. W. (1988). Structural equation modeling in practice: A review and recommended two-step approach. Psychological Bulletin, 103(3), 411.

Andreeva, T., \& Garanina, T. (2016). Do all elements of intellectual capital matter for organizational performance? Evidence from Russian context. Journal of Intellectual Capital, 17(2), 397-412.

Ball, K., \& Lewis, V. (2016). Implementing the balanced scorecard as a strategic planning and performance management tool: A case study from McMaster University Library. In Quality and the Academic Library (pp. 259-265). Chandos Publishing.

Bontis, N., Chua Chong Keow, W., \& Richardson, S. (2000). Intellectual capital and business performance in Malaysian industries. Journal of Intellectual Capital, 1(1), 85-100.

Capozza, C., \& Divella, M. (2019). Human capital and firms' innovation: evidence from emerging economies. Economics of Innovation and New Technology, 28(7), 741-757.

Charitou, C. D., \& Markides, C. C. (2002). Responses to disruptive strategic innovation. MIT Sloan Management Review, 44(2), 55-64.

Chege, S. M., \& Wang, D. (2020). The influence of technology innovation on SME performance through environmental sustainability practices in Kenya. Technology in Society, 60, 101210.

Derrick, P., \& Soren, K. (2007). A Framework for Strategic Innovation. Innovation Point LLC.

Donkor, J., Donkor, G. N. A., \& Kwarteng, C. K. (2018). Strategic planning and performance of SMEs in Ghana. Asia Pacific Journal of Innovation and Entrepreneurship.

Edinburgh Group (2013). Growing the global economy through SMEs, available at:http://www.edinburghgroup.org/media/2776/edinburgh_group_research_growing_the_global_economy_through_smes.pdf, accessed 30.12.2013. Elo.

Fararah, F. S., \& Al-Swidi, A. K. (2013). The role of the perceived benefits on the relationship between service quality and customer satisfaction: a study on the Islamic microfinance and SMEs in Yemen using PLS approach. Asian Social Science, $9(10), 18$.

Fararah, F. S., Al-Swidi, A. K., \& Yusoff, W. S. B. W. (2014). Business Development Services Provided by Islamic Microfinance Institutions and Customer Satisfaction: The Mediation Role of Perceived Benefits. A Study on SMEs in Yemen. Journal of Entrepreneurship and Business Innovation, 1(1), 60-78.

Franklin, M. E., \& Foa, E. B. (2002). Cognitive behavioral treatments for obsessive compulsive disorder. A guide to treatments that work, 2, 367-386.

Global innovation index (2017). Stronger Innovation Linkages for Global.

Graetz, F. (2002). Strategic thinking versus strategic planning: towards understanding the complementarities. Management decision.

Gupta, A. K., \& Govindarajan, V. (1984). Business unit strategy, managerial characteristics, and business unit effectiveness at strategy implementation. Academy of Management Journal, 27(1), 25-41.

Hejazi, R., Ghanbari, M., \& Alipour, M. (2016). Intellectual, Human and Structural Capital Effects on Firm Performance as Measured by Tobin's Q. Knowledge and Process Management, 23(4), 259-273.

Henderson, A. E., \& Hines, R. D. (2019). Using Concepts from Strategic Planning. Data Strategy in Colleges and Universities: From Understanding to Implementation.

Heracleous, L. (1998). Strategic thinking or strategic planning?. Long Range Planning, 31(3), 481-487.

Horibe, F. (2016). Creating the innovation culture: Leveraging visionaries, dissenters, and other useful troublemakers in your organization. VisionArts Inc.

Kaplan, R.S., \& Norton, D.P. (1992). The balanced scorecard- measures that drive performance. Harvard Business Review, January/February, pp. 71-90.

Kemp, R. L. (2018). Strategic planning in local government. Routledge.

Khalique, M., Nassir Shaari, J. A., \& Isa, A. H. B. M. (2011). Intellectual capital and its major components. International Journal of Current Research, 3(6), 343.

Khan, Z., Hussain, M., Shahbaz, M., Yang, S., \& Jiao, Z. (2020). Natural resource abundance, technological innovation, and human capital nexus with financial development: a case study of China. Resources Policy, 65, 101585.

Liedtka, J.M. (1998). Linking strategic thinking with strategic planning. Strategy \& Leadership, 26(4), 30-5. 
Lindsay, W.M., \& Rue, L.W. (1980). Impact of the business environment on long range planning process: a contingency view. Academy of Management Journal, 23(3), 385-404.

Liu, C. H. (2017). The relationships among intellectual capital, social capital, and performance-The moderating role of business ties and environmental uncertainty. Tourism Management, 61, 553-561.

Mahmood, N., Jianfeng, C., Jamil, F., Karmat, J., Khan, M., \& Cai, Y. (2015). Business incubators: Boon or boondoggle for SMEs and economic development of Pakistan. International Journal of u-and e-Service, Science and Technology, 8(4), 147-158.

Ministry of Yemen (2015). Ministry of Industry and Trade.

Ministry of Yemen (2016). Ministry of Technical Education and Vocational Training.

Ministry of Yemen (2017). Ministry of Industry and Trade.

Ministry of Yemen (2019). Ministry of Industry and Trade.

Mintzberg, H., Ahlstrand, B., \& Lampel, J. (2005). Strategy Safari: a guided tour through the wilds of strategic management. Simon and Schuster.

Mokhtar, S. S. M., Yusoff, R. Z., \& Ahmad, A. (2014). Key elements of market orientation on Malaysian SMEs performance. International Journal of Business and Society, 15(1), 49.

Mowery, D. C., Nelson, R. R., Sampat, B. N., \& Ziedonis, A. A. (2015). Ivory tower and industrial innovation: Universityindustry technology transfer before and after the Bayh-Dole Act. Stanford University Press.

Napier, N.K. and Albert, M.S. (1990). East Asian and American perspectives on thinking strategically: the leopard and his spots. Asia Pacific Journal of Human Resources, 28(4), 40-50.

Nusair, A. Y. A., \& Osman, M. H. M. (2016). An empirical study of the effect of strategic planning on Yemeni SME performance. International Journal of Advanced Research, 4(8), 455-463.

OECD (2017). Enhancing the contributions of SMEs in a global and digitalized economy. Paris: Meeting of the OECD council at ministerial level, 7 - 8 June, 2017.

Omar, S. (2019). Strategic Planning in Education: A Case Study of BCAA in the United Arab Emirates. In Strategic Thinking, Planning, and Management Practice in the Arab World (pp. 238-249). IGI Global.

O'Shannassy, T. (1999). Strategic thinking: a continuum of views and conceptualisation. RMIT Business.

Porter, M. E. (1991). Know Your Place: How to Assess the Attractiveness of your Industry and your Company's Position in it.

Ren, S., Eisingerich, A. B., \& Tsai, H. T. (2015). How do marketing, research and development capabilities, and degree of internationalization synergistically affect the innovation performance of small and medium-sized enterprises (SMEs)? A panel data study of Chinese SMEs. International Business Review, 24(4), 642-651.

Rothwell, W. J., \& Kazanas, H. C. (2003). Planning and managing human resources: strategic planning for human resources management. Human Resource Development.

Sharabati, A. A. A., Naji Jawad, S., \& Bontis, N. (2010). Intellectual capital and business performance in the pharmaceutical sector of Jordan. Management decision, 48(1), 105-131.

Sivalogathasan, V., \& Wu, X. (2015). Impact of organization motivation on intellectual capital and innovation capability of the textile and apparel industry in Sri Lanka. International Journal of Innovation Science, 7(2), 153-168.

SkyNews. (2012), "Retrieved from https://www.youtube.com/watch?v=ZW7KWVEdQOY /2012.

Statista. (2019), "https://www.statista.com/statistics/809082/unemployment-rate-in-yemen/".

Stumpf, S. A. (1989). Work Experiences that Stretch Managers' Capacities for Strategic Thinking. Journal of Management Development, 8(5), 31-39.

Subramaniam, M., \& Youndt, M. A. (2005). The influence of intellectual capital on the types of innovative capabilities. Academy of Management Journal, 48(3), 450-463.

Tavakoli, I., \& Lawton, J. (2005). Strategic thinking and knowledge management. Handbook of business strategy.

Training, M. T. D. (2011). Thinking Strategically. Bookboon.

World Bank (2015) Jobs and Privilege: Unleashing the Employment potential of the Middle East and North Africa, the World Bank.

World Bank (2015). The republic of Yemen: Unlocking the potential for economic growth. World Bank Reports No. 102151YE.

World Bank. (2016). Washington, D.C. U.S.A. Retrieved from http://www.worldbank.org.

Yadav, A., Pal, N., Patra, J., \& Yadav, M. (2020). Strategic planning and challenges to the deployment of renewable energy technologies in the world scenario: its impact on global sustainable development. Environment, Development and Sustainability, 22(1), 297-315.

Yang, X. (2014). Different choice of strategic innovation among companies in China market. Journal of Science and Technology Policy Management, 5(2), 106-121.

YMIT (2014). General report of the result of the comprehensive industrial survey 2010. Yemen Ministry of trade and industry.

Zahra, S. A., \& Nambisan, S. (2012). Entrepreneurship and strategic thinking in business ecosystems. Business Horizons, 55(3), 219-229.

Zerenler, M., Hasiloglu, S. B., \& Sezgin, M. (2008). Intellectual capital and innovation performance: empirical evidence in the Turkish automotive supplier. Journal of Technology Management \& Innovation, 3(4), 31-40. 


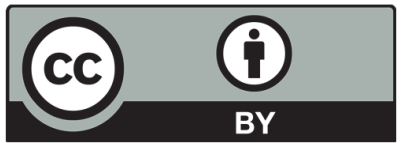

(C) 2020 by the authors; licensee Growing Science, Canada. This is an open access article distributed under the terms and conditions of the Creative Commons Attribution (CC-BY) license (http://creativecommons.org/licenses/by/4.0/). 